\title{
Analysis of energy requirements versus comfort levels for the integration of phase change materials in buildings
}

\author{
Martin Vautherot ${ }^{\mathrm{a}}$, François Maréchal ${ }^{\mathrm{a}}$, Mohammed M. Farid ${ }^{\mathrm{b}, *}$ \\ a Ecole Polytechnique Fédérale de Lausanne, 1015 Lausanne, Switzerland \\ b Department of Chemical \& Materials Engineering, The University of Auckland, 1010 Auckland, New Zealand
}

\section{A R T I C L E I N F O}

\section{Article history:}

Received 10 December 2014

Received in revised form

4 March 2015

Accepted 12 March 2015

Available online 31 March 2015

Keywords:

PCM

Design builder

Energy savings

Comfort

Multi-objective

Gypsum board

Residential HVAC

\begin{abstract}
A B S T R A C T
This paper investigates the importance of the design parameters when looking at possible energy savings and comfort enhancement in a building using Phase Change Materials (PCMs). Computer based simulations are performed using a simulation software for modelling a house and its thermal behaviour over a year. It is found that by varying the heating set point and the phase change (melting) temperature range of the PCM, significant changes can be observed. Some poor scenarios show that the integration of PCM can increase both the discomfort (up to 6\% more discomfort hours) and the energy requirements (up to $25 \%$ more energy needed). On the other hand, appropriate scenarios bring significant energy savings (up to $33 \%$ less energy needed) and comfort enhancement (up to $31 \%$ less discomfort hours). This highlights the strong need for a clever design when integrating PCM into buildings. The goal is to find a trade-off between energy savings and comfort enhancement. The PCM with a phase change temperature range between $21^{\circ} \mathrm{C}$ and $26^{\circ} \mathrm{C}$ shows the best results. The study is based on climate conditions for Auckland City in New Zealand but most of the conclusions drawn can be applied to any climate.
\end{abstract}

(c) 2015 Elsevier Ltd. All rights reserved.

\section{Introduction}

The use of PCMs as a mean for thermal energy storage in buildings is complex but can provide multiple advantages. The interest of PCMs is that by going through a phase change, large amounts of heat can be stored and released. Building materials store thermal energy through sensible heat which requires a temperature difference while a PCM involves the latent heat at a selected temperature, therefore requiring lower temperature difference for the heat storage. These materials have been investigated and still are for their properties which can be compared using existing reviews [1-3].

A convenient integration of PCMs in buildings is through the use of impregnated gypsum boards, which are commonly added as an internal layer inside a building. This low-cost component provides a suitable structure for PCM containment which is great for both new constructions and retrofitting. One of the main interests of the gypsum board is that it is the innermost layer for most constructions. The replacement of an existing conventional gypsum board is therefore an easy task [4,5]. There are three methods of how PCM can be incorporated into the construction material:

\footnotetext{
* Correspondence to: Department of Chemical and Materials Engineering. The University of Auckland. Private Bag 92019, Auckland, New Zealand. Fax: +649-3737463.

E-mail address: m.farid@auckland.ac.nz (M.M. Farid).
}

direct incorporation, immersion and encapsulation. Micro-encapsulation prevents problems associated with PCM volume change and provides greater heat exchange area which increases heat transfer rate. Micro-encapsulation is the most appropriate when using gypsum boards, it prevents PCM leakage shows good cycling stability [6].

The main interest when using PCMs in buildings is that they should have the ability to reduce indoor temperature swings without any external help. To do so, the indoor temperature must vary across the phase change temperature range of the PCM. When the material goes from solid-phase to liquid-phase through a melting process, it absorbs large amounts of heat and therefore slows down the temperature rise that would otherwise occur inside the building. When the ambient temperature drops, the PCM goes through a solidification process and releases heat which has the effect of slowing down the decrease in temperature inside the building [7].

Not only can the integration of PCM in buildings reduce the energy requirements, but it can also enhance comfort. By reducing the indoor temperature variations, buildings rely less on heating, ventilation and air conditioning (HVAC) system. PCMs can also reduce the period of heating and cooling as temperature peaks can be avoided. At the moment the emphasis in most investigations on PCMs is mainly about the energy consumption and not about comfort levels. However the goal of an HVAC system is to provide comfortable conditions for people, therefore a better 
understanding on how these two parameters vary in the presence of PCMs is necessary since it has not been studied in the literature before. Also, the question of the optimum choice PCM phase change temperature range is not assessed in the literature and turns out to be of great importance as investigated in this paper.

The objectives of this work are: (1) to show how the HVAC set points influence both energy requirements and comfort; (2) to investigate how the phase change temperature range of PCM influences the energy consumption and the level of comfort; (3) to show that appropriate PCM designs depend on the trade-off between energy requirements and comfort levels.

\section{Methodology of the investigation for a typical house using computer simulation}

\subsection{Development of a building simulation model}

Computer-based simulations show several advantages when it can be validated against past experimental measurements. An important fact is that they save time and can be used to perform a study over a year-round within a few hours of simulation. It also allows great flexibility to show the influence of few parameters, while keeping all the other factors constant. To perform the calculations, the interface Design Builder which is based on the other software Energy Plus is used [8]. The latter allows the integration of PCMs and has been validated in previous studies [9-11].

The University of Auckland built two identical offices (with and without PCM) provided with a data collection system. The offices are built in Tamaki near Auckland where the climate is temperate. The two offices have been modelled and the results of the simulations are compared with the experimental data collected over a week as shown in Fig. 1. The thin blue dashed line shows the indoor air temperature as obtained from the simulation, the black solid bold line shows the measured indoor temperature, and the light green solid line shows the outside temperature.

The office with the PCM-impregnated gypsum boards is the one which was modelled and shown in Fig. 1. It can be observed that the gap between the experimental and simulated curves is reasonably small. This confirms the fact that simulation software can be trusted as it takes well into account the integration of PCM. $\mathrm{T}$ from the experimental measurements may have come from the integration of the properties of the construction materials indicated to the software and from the difficulty of measuring some of the parameters such as infiltration rate.

\subsection{Modelling of a typical house}

\subsubsection{Geometry and materials}

Following model validation, simulations were conducted for a typical two-story house in Auckland. The construction of the house is based on real construction plans and a typical materials structure. It is a two-story family house for five people. The geometry was therefore added in the simulation software and is shown in Fig. 2. A few simplifications have been done to speed up the simulations while keeping the results relevant. The two "Master bedrooms" are merged with their respective "En suite". The "Living room" and the "Hall" of the first floor are merged together. Finally the three "Bedrooms" of the first floor are merged together. The black arrow in the figure points towards North. This North facing orientation is explained by the fact that the house is situated in the Southern Hemisphere. Every bedroom and living room has two windows to let as much light as possible in.

The characteristics of the materials provided to the software and every type of structure (roof, walls, partitions etc...) are given in Tables 1 and 2. It must be kept in mind that the PCM is added to the gypsum board, therefore it has a significant influence on the house's thermal mass. The total surface area of gypsum board is $810.5 \mathrm{~m}^{2}$ for the whole house with a floor surface area of $256 \mathrm{~m}^{2}$.

\subsection{2. $H V A C$}

In order to run a realistic study for the house, several assumptions had to be made to define the overall system. The simulations only give the energy loads needed and no HVAC system was defined. The goal of the study is to observe the heating and cooling loads needed, and not how to provide them. A zoning in the house is assumed so that every heated or cooled room receives the appropriate amount of heating or cooling needed to meet the set points. The loads are assumed to be variable so that the temperatures remain constant once the set points are reached, and the power adapts. In order to have a realistic design, all main rooms are assumed to have an HVAC system. Therefore only the bathroom, toilet and garage are left with no HVAC.

\subsubsection{Occupancy}

Regarding the occupancy, the house is assumed to be occupied

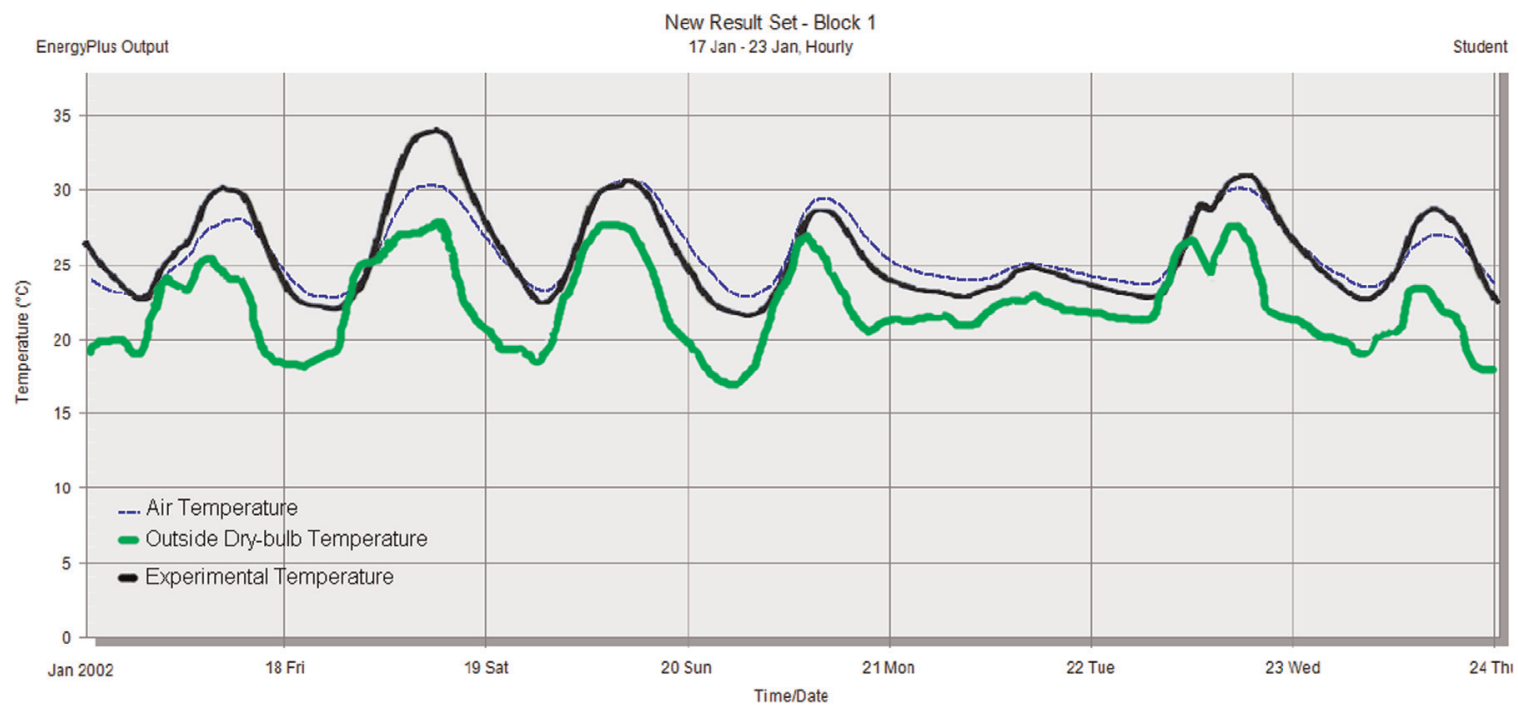

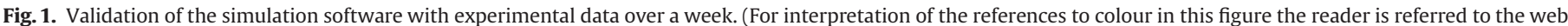
version of this article.) 


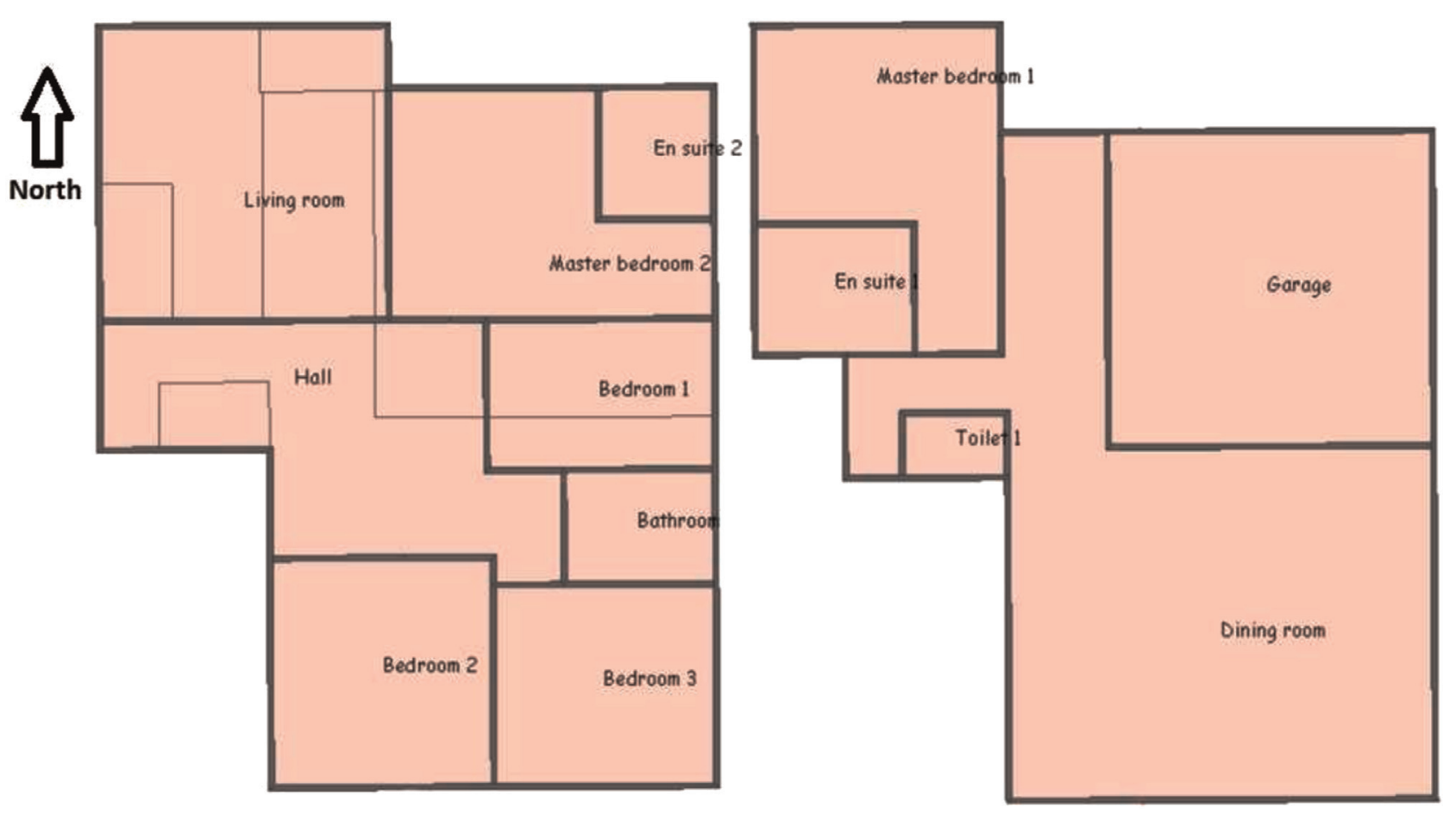

Fig. 2. View of the geometry of the simulated house (first floor on the left and ground floor on the right).

by a family of five people. The occupancy schedule is of a great importance when doing this type of simulation and was kept as realistic as possible. On weekdays, people leave the house at 8 a.m. and come back at 5 p.m. Then they spend their time between the bedrooms and the common rooms (kitchen, living room and hall) until 10 p.m. when everybody goes to their respective bedrooms. On the weekend, people stay in the house the whole day and spend their time between the bedrooms and common rooms from 9 a.m. to 10 p.m., after that they go to their respective bedrooms. The HVAC schedule matches with the room occupancy, and is therefore assumed to operate when there are people in the rooms. Meaning that when the people are not present the HVAC system is off, and the people start the HVAC system when they arrive at home. Another aspect of PCMs is the ability to perform peak load shifting but this is not investigated in this paper [11].

\subsection{Inputs in the model}

The two variable parameters in this study are the heating set point and the phase change temperature range of the PCM used in the gypsum board. In this study, 5 heating set points and 6 types of PCMs were tested. This yields a total of 30 combinations.

\subsubsection{Heating set point}

The heating set point goes from $20^{\circ} \mathrm{C}$ to $24^{\circ} \mathrm{C}$ while the cooling set point is kept constant at $25^{\circ} \mathrm{C}$. The choice to vary the heating set point is done because in New Zealand, most of the energy requirements come from heating. The set point defines the target that the air temperature must reach. A minimum set point temperature of $18^{\circ} \mathrm{C}$ is chosen for night time in the bedrooms. Therefore, the HVAC system changes its target after 10 p.m. in order to reduce the energy requirements and maintain a comfortable minimum sleeping temperature [12].

\subsubsection{Types of gypsum boards}

Six types of gypsum boards are tested: 5 using PCMs with different melting ranges, and one conventional gypsum board having no PCM. The gypsum board has a thickness of $13 \mathrm{~mm}$ and a density of $600 \mathrm{~kg} / \mathrm{m}^{3}$ while the PCM has a density of $770 \mathrm{~kg} / \mathrm{m}^{3}$ which leads to a density of $643 \mathrm{~kg} / \mathrm{m}^{3}$ for the PCM-impregnated gypsum board [13]. The latent heat storage density of the PCMimpregnated gypsum board is $33.5 \mathrm{~kJ} / \mathrm{kg}$ (25\%weight of pure PCM with a latent heat of $134 \mathrm{~kJ} / \mathrm{kg}$ ) and takes effect only during the phase change. The latent heat is assumed to be distributed linearly throughout the phase change process. It is chosen to keep a constant phase change temperature range of $5^{\circ} \mathrm{C}$ which is a realistic assumption for most commercial PCMs. A narrower range would increase significantly the cost of PCM. Hence, the 6 different gypsum boards are:

No PCM/PCM 18-23 ${ }^{\circ} \mathrm{C} / \mathrm{PCM} 19-24^{\circ} \mathrm{C} / \mathrm{PCM} 20-25^{\circ} \mathrm{C} / \mathrm{PCM} 21-$ $26^{\circ} \mathrm{C} / \mathrm{PCM} 22-27^{\circ} \mathrm{C}$. Even though the economic aspects are not at the heart of the study, it must be said that all of the suggested PCMs are assumed to have the same estimated cost of $\$ 3 \mathrm{NZD} / \mathrm{kg}$ which is an expected future price [14]. One scenario is therefore defined as a combination of both inputs. For example "PCM 21-26 $22{ }^{\circ} \mathrm{C}$ " refers to the scenario with a heating set point of $22{ }^{\circ} \mathrm{C}$ and

Table 1

Construction of the house with the different materials

\begin{tabular}{|c|c|c|c|c|c|c|c|c|c|}
\hline & Exterior wall & Interior wall & $\begin{array}{l}\text { Ground } \\
\text { floor }\end{array}$ & Interior floor & Roof & Windows & Doors & $\begin{array}{l}\text { Garage } \\
\text { door }\end{array}$ & Roof floor \\
\hline $\begin{array}{l}\text { Outer layer } \\
\text { Inner layer }\end{array}$ & $\begin{array}{l}\text { Brick } \\
\text { Air gap } 45 \mathrm{~mm} \\
\text { Wall insulation } \\
\text { Gypsum board }\end{array}$ & $\begin{array}{l}\text { Gypsum board } \\
\text { Air gap } 90 \mathrm{~mm} \\
\text { Gypsum board }\end{array}$ & $\begin{array}{l}\text { Concrete } \\
\text { Carpet }\end{array}$ & $\begin{array}{l}\text { Gypsum board } \\
\text { Air gap } 240 \mathrm{~mm} \\
\text { Gypsum board }\end{array}$ & Roof tiles & Double glazing & Wood & Steel sheet & $\begin{array}{l}\text { Roof insulation } \\
\text { Gypsum board }\end{array}$ \\
\hline
\end{tabular}


Table 2

Properties of the construction materials.

\begin{tabular}{|c|c|c|c|c|c|c|c|c|c|c|}
\hline & Unit & Steel sheet & Carpet & Wood & Gypsum board & Wall insulation & Roof insulation & Concrete & Brick & Tiles \\
\hline Thickness & {$[\mathrm{m}]$} & 0.002 & 0.001 & 0.035 & 0.013 & 0.09 & 0.17 & 0.085 & 0.07 & 0.014 \\
\hline Conductivity & {$[\mathrm{W} / \mathrm{m} \mathrm{K}]$} & 13.8 & 0.056 & 0.14 & 0.25 & 0.04 & 0.04 & 1.13 & 0.84 & 0.73 \\
\hline Density & {$\left[\mathrm{kg} / \mathrm{m}^{3}\right]$} & 7817 & 213 & 650 & 600 & 12 & 12 & 2000 & 1700 & 2500 \\
\hline Specific heat & [J/kg K] & 460 & 1400 & 1200 & 1089 & 840 & 840 & 1000 & 800 & 773 \\
\hline
\end{tabular}

with a PCM having a phase change temperature range between $21^{\circ} \mathrm{C}$ and $26^{\circ} \mathrm{C}$.

The total storage capacity of the PCM in the whole house is given in Eq. (1)

$\dot{Q}_{\text {storage }}=A_{G B} e_{G B} \rho_{P C M G B} w t \%$ PCM $h_{l a t, P C M}=227 \mathrm{MJ}$

where $\dot{Q}_{\text {storage }}$ in [MJ] is the storage capacity of PCM in the house; $A_{G B}=810.5 \mathrm{~m}^{2}$ is the total surface area of gypsum board in the house; $e_{G B}=0.013 \mathrm{~m}$ is the thickness of the gypsum board; $\rho_{P C M G B}=643 \mathrm{~kg} / \mathrm{m}^{3}$ is the density of the PCM-impregnated gypsum board; $w t \%$ PCM $=0.25$ is the weight ratio of PCM in the gypsum board; $h_{l a t, P C M}=134 \mathrm{~kJ} / \mathrm{kg}$ is the latent heat of the PCM.

\subsection{Outputs of the model}

The goal of this study is to observe two outputs: the comfort level and energy requirement. Both are factors of high importance and they go together creating a trade-off between energy savings and comfort. However, some scenarios show better combination and the target is to see what are these scenarios.

\subsubsection{Comfort level}

The comfort level is measured by the number of discomfort hours, i.e. the number of hours during which the comfort conditions as defined by the standard ASHRAE 55-2004 are not met [15]. The standard states that if there is someone in the room and the conditions of temperature and humidity depicted in Fig. 3 are not satisfied, there is discomfort. It considers both the operative temperature and humidity ratio when deciding whether or not there is comfort. The humidity levels are taken from the weather file of the city and are assumed not to be controlled during the simulation.

When measuring the comfort level based on the standard, it is the operative temperature which is considered and not the air temperature which is the target of the HVAC. The operative temperature is an average between the air and radiant temperature, the latter being dependant on the wall temperature. The radiant temperature has a strong influence on the feeling of warmth or coldness for a person inside a room. The addition of thermal mass

Summer $(0.5 \mathrm{Clo})$

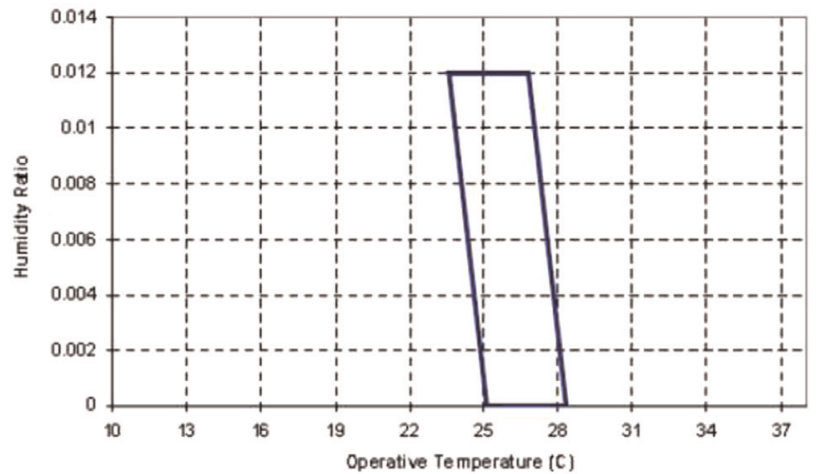

Table 3

Total number of hours of occupancy per zone in the house over a year

\begin{tabular}{ll}
\hline & Occupancy [hr/year] \\
\hline Ground floor: Master Bedroom 1 & 6150 \\
Ground floor: Dining room & 2918 \\
Ground floor: Toilet & 365 \\
First floor: Master Bedroom 2 & 6150 \\
First floor: Hall and Living room & 2918 \\
First floor: Bathroom & 730 \\
First floor: Other Bedrooms & 6150 \\
Total & 25,381 \\
\hline
\end{tabular}

with the PCM-impregnated gypsum board reduces the temperature swings of the building's envelope, and therefore influences the feeling of comfort. The simulation software provides the comfort level as the total number of discomfort hours for the rooms usage as depicted in Table 3. The garage is assumed to be unoccupied and rooms of the same type are merged together as explained before.

It has to be kept in mind however that the concept of comfort is a subjective one, and therefore may vary with external parameters such as culture, activity, age, gender, etc.

\subsubsection{Energy requirements}

Energy requirement is the main focus of most studies involving the integration of PCMs and is the most critical parameter. The energy requirements define the consumption (varying with the HVAC system). From that, the annual costs of the consumed energy can be calculated. This decides if an investment in PCMs is economically viable and determines people's decisions to use PCM in their house. In this investigation however, only the heating and cooling ideal loads are given. A distinction is made between heating and cooling loads as it will be seen that they vary differently with the addition of PCM in the construction.

\section{Results and discussion}

Table 4 summarizes the outputs of the annual 30 year-round

Fig. 3. Comfort zones according to ASHRAE Standard 55-2004 used in the simulation software [15].

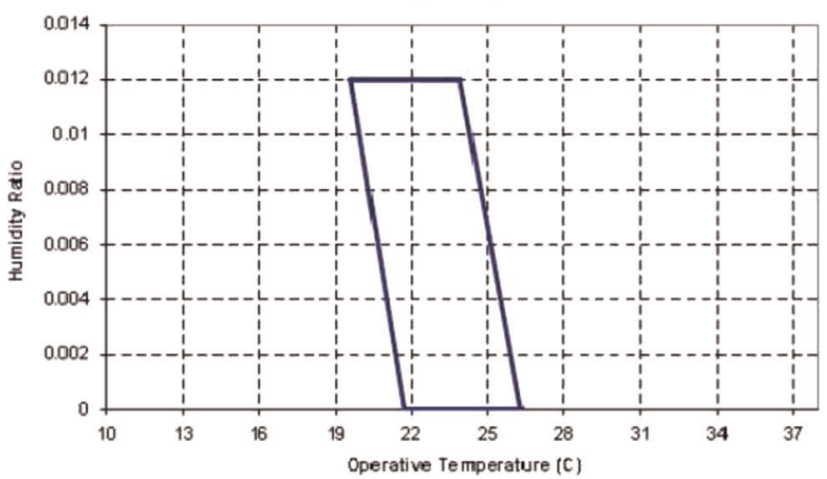


Table 4

Results for the 30 year-round simulations investigating the comfort and energy requirements

\begin{tabular}{|c|c|c|c|c|c|c|}
\hline Design & Heating load [kWh] & Cooling load [kWh] & Total load [kWh] & Discomfort hours [hours] & Energy savings [\%] & Discomfort savings [\%] \\
\hline No PCM $20^{\circ} \mathrm{C}$ & 3171 & 1410 & 4581 & 15,822 & & \\
\hline PCM 18-23 $20^{\circ} \mathrm{C}$ & 2926 & 597 & 3523 & 16,790 & 23 & -6 \\
\hline PCM 19-24 $20^{\circ} \mathrm{C}$ & 2734 & 450 & 3184 & 16,236 & 31 & -3 \\
\hline PCM 20-25 $20^{\circ} \mathrm{C}$ & 2745 & 321 & 3066 & 14,953 & 33 & 5 \\
\hline PCM 21-26 $20^{\circ} \mathrm{C}$ & 2815 & 251 & 3067 & 14,546 & 33 & 8 \\
\hline PCM 22-27 $20^{\circ} \mathrm{C}$ & 2868 & 254 & 3122 & 14,921 & 32 & 6 \\
\hline No PCM $21^{\circ} \mathrm{C}$ & 4020 & 1432 & 5452 & 13,799 & & \\
\hline PCM $18-2321^{\circ} \mathrm{C}$ & 4407 & 604 & 5011 & 14,335 & 8 & -4 \\
\hline PCM 19-24 $21^{\circ} \mathrm{C}$ & 4038 & 454 & 4491 & 13,647 & 18 & 1 \\
\hline PCM 20-25 $21^{\circ} \mathrm{C}$ & 3734 & 322 & 4057 & 12,573 & 26 & 9 \\
\hline PCM 21-26 $21^{\circ} \mathrm{C}$ & 3680 & 253 & 3933 & 12,561 & 28 & 9 \\
\hline PCM 22-27 $21^{\circ} \mathrm{C}$ & 3725 & 256 & 3981 & 12,932 & 27 & 6 \\
\hline No PCM $22{ }^{\circ} \mathrm{C}$ & 5080 & 1466 & 6547 & 11,435 & & \\
\hline PCM 18-23 $22^{\circ} \mathrm{C}$ & 6284 & 628 & 6911 & 10,415 & -6 & 9 \\
\hline PCM 19-24 $22^{\circ} \mathrm{C}$ & 5859 & 468 & 6327 & 9900 & 3 & 13 \\
\hline PCM 20-25 $22{ }^{\circ} \mathrm{C}$ & 5332 & 331 & 5663 & 9642 & 13 & 16 \\
\hline PCM 21-26 $22{ }^{\circ} \mathrm{C}$ & 4920 & 257 & 5177 & 9977 & 21 & 13 \\
\hline PCM 22-27 $22{ }^{\circ} \mathrm{C}$ & 4820 & 259 & 5079 & 10,495 & 22 & 8 \\
\hline No PCM $23^{\circ} \mathrm{C}$ & 6338 & 1517 & 7855 & 10,715 & & \\
\hline PCM $18-2323^{\circ} \mathrm{C}$ & 8474 & 682 & 9155 & 8304 & -17 & 23 \\
\hline PCM $19-2423^{\circ} \mathrm{C}$ & 8055 & 501 & 8556 & 8280 & -9 & 23 \\
\hline PCM $20-2523^{\circ} \mathrm{C}$ & 7453 & 353 & 7806 & 8224 & 1 & 23 \\
\hline PCM 21-26 $23^{\circ} \mathrm{C}$ & 6774 & 272 & 7046 & 8635 & 10 & 19 \\
\hline PCM 22-27 $23^{\circ} \mathrm{C}$ & 6284 & 269 & 6553 & 9496 & 17 & 11 \\
\hline No PCM $24^{\circ} \mathrm{C}$ & 7786 & 1592 & 9378 & 10,287 & & \\
\hline PCM $18-2324^{\circ} \mathrm{C}$ & 10,895 & 799 & 11,694 & 7113 & -25 & 31 \\
\hline PCM 19-24 $24^{\circ} \mathrm{C}$ & 10,541 & 573 & 11,114 & 7116 & -19 & 31 \\
\hline PCM 20-25 $24^{\circ} \mathrm{C}$ & 9935 & 398 & 10,332 & 7054 & -10 & 31 \\
\hline PCM 21-26 $24^{\circ} \mathrm{C}$ & 9155 & 304 & 9460 & 7431 & -1 & 28 \\
\hline PCM 22-27 $24^{\circ} \mathrm{C}$ & 8357 & 296 & 8653 & 8512 & 8 & 17 \\
\hline
\end{tabular}

simulations based on the same year's meteorological data. The results are sorted by constant heating set points to make relevant comparisons depending on the targeted temperature.

By keeping the heating set point constant, energy savings can be compared for the designs with PCM-impregnated gypsum boards. Therefore a negative value in the savings means that instead of bringing better conditions, PCM makes it worse.

This way of presenting the data is to emphasise the fact that there are several acceptable solutions.

The discomfort savings index is defined as in Eq. (2) and is based on the number of hours when there are people in the rooms while the comfort conditions are not met.

Discomfort savings $=\frac{\left(T_{\text {Discomfort, No PCM }}-T_{\text {Discomfort, PCM }}\right)}{T_{\text {Discomfort, No PCM }}} 100[\%]$

where Discomfort savings in [\%] is the comfort improvement from the integration of PCMs; $\mathrm{T}_{\text {discomfort,PCM }}$ and $\mathrm{T}_{\text {discomfort,No PCM }}$ are respectively the yearly number of hours of discomfort for a case with and without PCM, respectively at a specific heating set point.

The results shown in Table 4 can be used to assist a designer to select a suitable combination of heating set point and PCM melting range based on energy consumption and comfort. It also allows better understanding on whether the savings are from the heating or cooling load. This is depicted in Fig. 4 and clearly shows that most of the savings occur during cooling in summer. In summer, PCM stores large quantity of coolness at night, while in winter PCM stores only the limited excess energy coming from solar radiation. In summer, the PCM slows down any rise in temperature which otherwise would involve a need for cooling. The heat stored can be released freely later when the temperature drops at night. Regardless of the heating set point, the cooling load decreases sharply when the melting temperature range of the PCM increases.

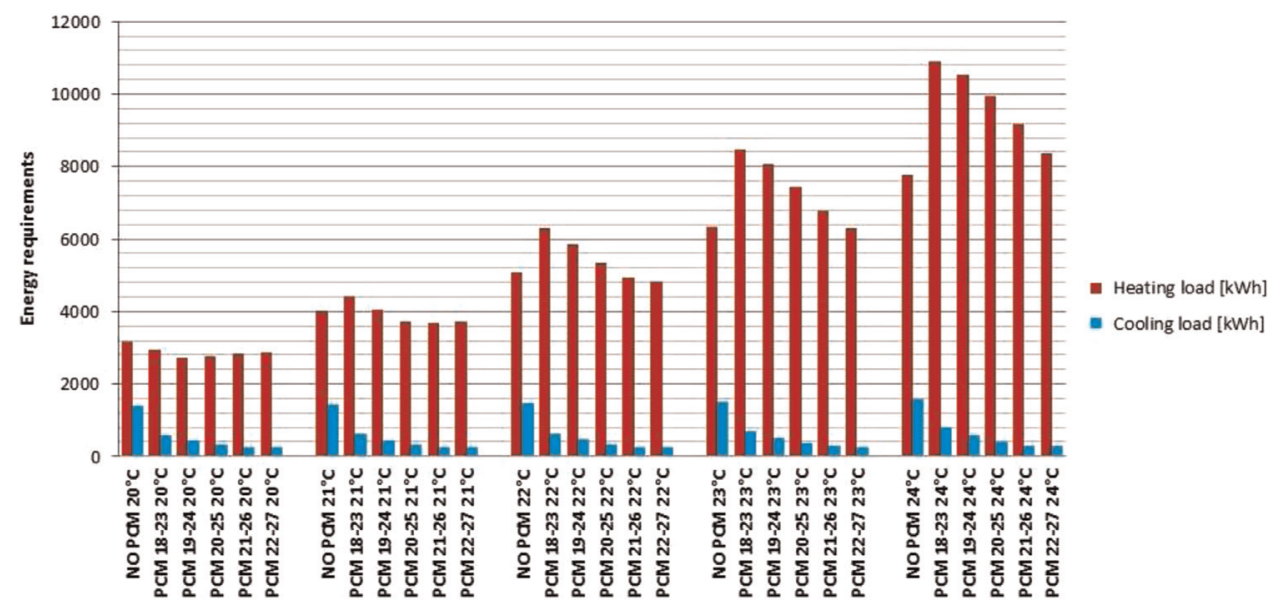

Fig. 4. Energy requirements for the different scenarios for the house. 


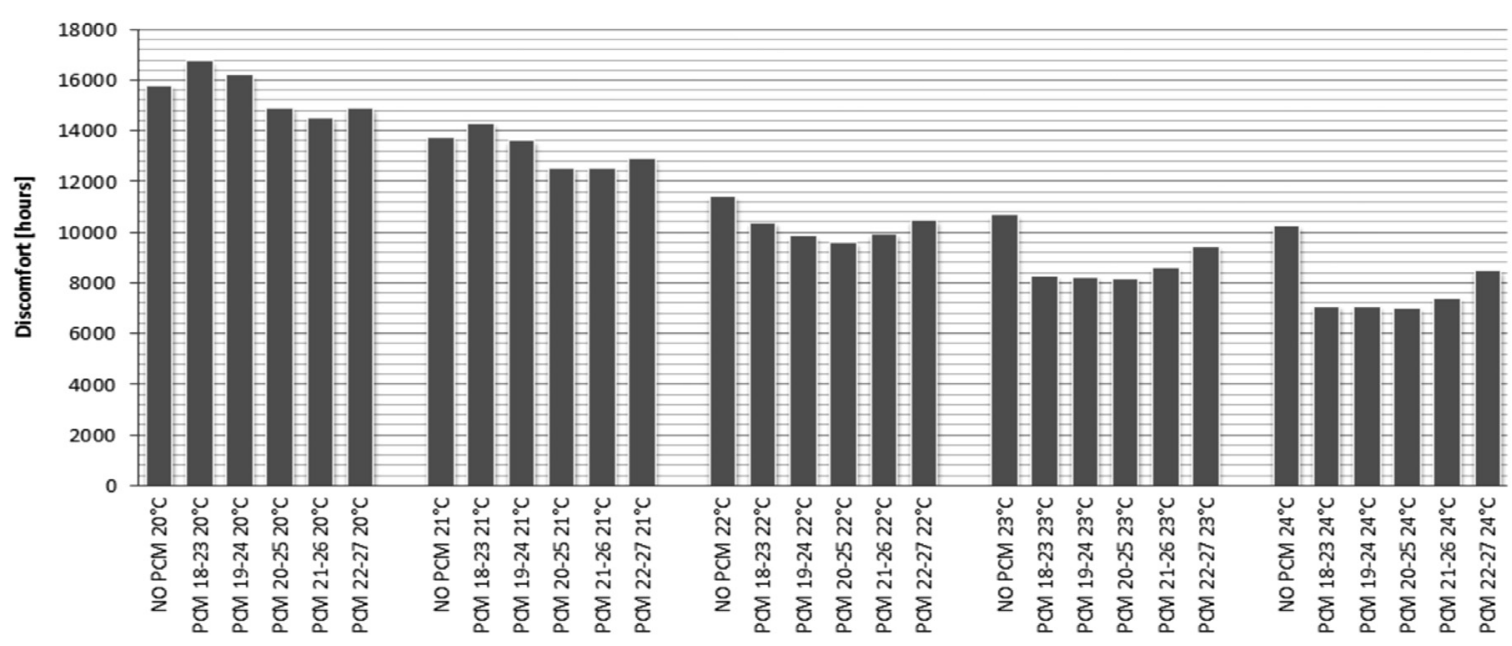

Fig. 5. Discomfort hours for the different scenarios for the house.

When looking at the heating loads, it is clear that the PCM brings little improvement and can also make it worse. The higher the heating set point, the more heating energy used and the less likely it is that the PCM integration will bring energy savings. This is explained by the fact that a heating set point situated within the phase change temperature range of the PCM will require extra energy to overcome the added thermal mass. For instance, a poor scenario "PCM 18-23 $24{ }^{\circ} \mathrm{C}$ " will not save the energy needed for heating in comparison with a basic design without PCM as a lot of heat is required to go from $18^{\circ} \mathrm{C}$ to the heating set point of $24^{\circ} \mathrm{C}$. The house is heated following a cyclic schedule, making it overcome the thermal mass every day to reheat it when people come home.

A clever scenario such as a "PCM 20-25 $20^{\circ} \mathrm{C}$ " on the other hand appears to be a good choice. The house can reach the heating set point easily without having to go through the latent heat. Any free energy (mainly solar radiation) from this point is going to be stored in the PCM as it starts to change phase.

These observations about the energy requirements highlight the need for a good design in order to make the integration of PCMs economically viable. A look at Fig. 5 brings more understanding about the comfort levels.

The first observation that can be seen here is that the total of comfort hours increases when more energy is put into the HVAC system which is expected. It also shows that the addition of PCM does not bring comfort enhancement in every case. This can be explained by the added thermal mass which can slow down the temperature rise and therefore prevent the rooms to reach the comfort zone in winter while it is the other way around in summer. One important point is that only some PCMs seem much more likely to bring comfort enhancement. For a fixed heating set point it is always either "PCM 20-25" or "PCM 21-26" which bring the more improvement compared to the case without PCM. This can be explained by the fact that both of these types of PCM match very well with the comfort zones depicted in Fig. 3 and therefore tend to keep longer the temperatures within these ranges for a longer time. One could say that the number of discomfort hours is high when assuming a total $25,381 \mathrm{~h}$ as given Table 3 . However, it must be noted that the night temperature set point of $18^{\circ} \mathrm{C}$ is not in the comfort zone from Fig. 3 even though it is a recommended temperature at night. This explains the relatively high level of discomfort from Fig. 6 even though in practice comfort is achieved.

As seen in Table 4, the scenarios providing more energy savings do not necessarily provide high comfort enhancement and vice versa. The idea is then to give for each heating set point an optimal design. A trade-off has to be made between energy and comfort. This trade-off is depicted in Fig. 6 and clearly shows the trend. As both outputs need to be minimised, the best designs are found on

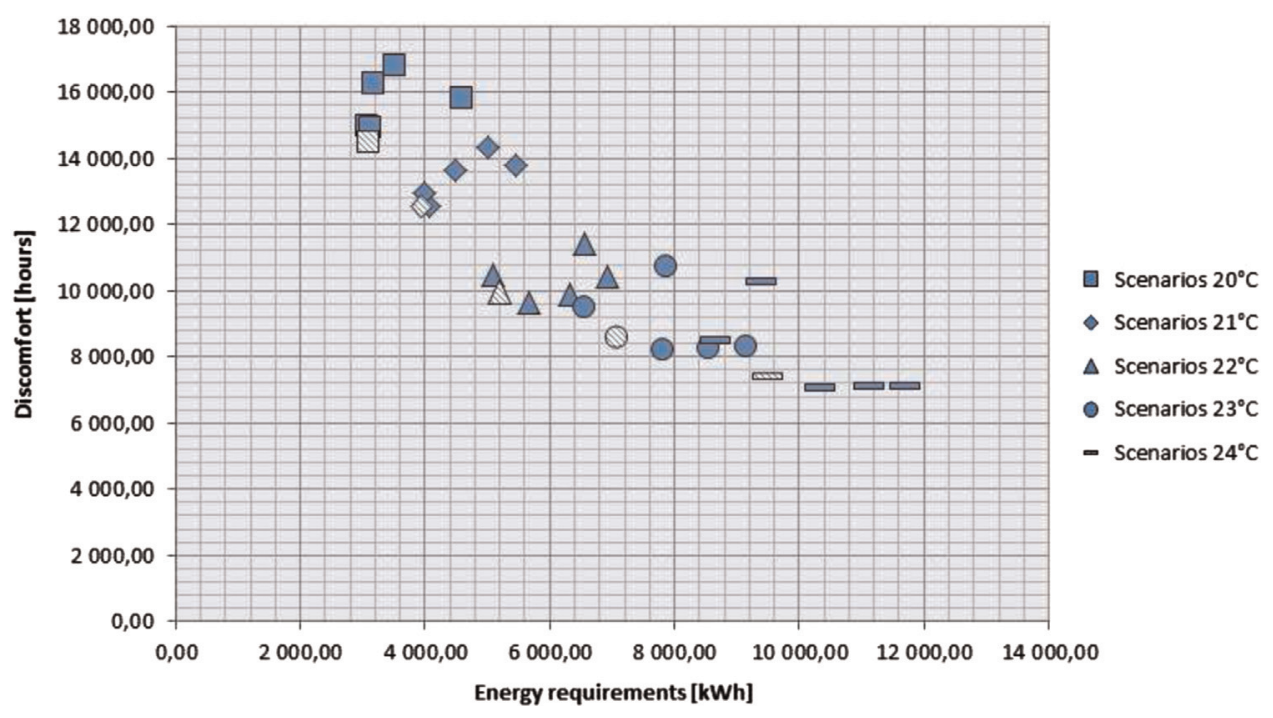

Fig. 6. Combination of the comfort levels with the energy requirements. 
the lower part and the left of the graph in Fig. 6. Then depending on the priorities of the household, the best design can be selected. For each heating set point, the chosen design is indicated with the non-solid shape symbols.

The suggested optimal scenarios are then: PCM 21-26 $20^{\circ} \mathrm{C} /$ PCM 21-26 $21^{\circ} \mathrm{C} / \mathrm{PCM} 21-2622^{\circ} \mathrm{C} / \mathrm{PCM} 21-2623^{\circ} \mathrm{C} / \mathrm{PCM} 21-26$ $24{ }^{\circ} \mathrm{C}$. This graphical analysis exhibits the fact that the PCM changing phase within the range $21-26^{\circ} \mathrm{C}$ brings the best tradeoff for every heating set point.

In order to have a better understanding of these results, two days were investigated in more detail. A typical day in summer and a typical day in winter. The winter analysis depicts a scenario without PCM, and two scenarios using PCMs (good and bad). The summer analysis shows only one scenario without PCM and a good scenario with PCM as PCMs always bring improvement.

The "air temperature" in solid line is the indoor temperature targeted by the HVAC system. Therefore some plateaus are seen when the HVAC is required as seen on the graphs. The "operative temperature" in dashed line includes the effect of radiation and is the one which determines the feeling of comfort. The HVAC load is depicted on the right to show how the different scenarios induce different heating and cooling loads.

The winter day is a typical weekday and it is chosen to show the scenario "No PCM $20^{\circ} \mathrm{C}$ " compared to the scenarios "PCM 20$2520^{\circ} \mathrm{C}$ " and "PCM 22-27 $20^{\circ} \mathrm{C}$ ". A constant heating set point and the analysis over the same room (Master bedroom on the first floor) give relevant results for a comparison of the influences of PCMs.

The results for this winter day are given in Figs. 7-9. As expected according to Table 4, the designs with PCM show lower heating requirements. The one with "No PCM" requires $3.61 \mathrm{kWh}$, the one with "PCM 20-25" requires $2.40 \mathrm{kWh}$ and the one with "PCM 22-27" requires $2.90 \mathrm{kWh}$. This is only for a room over a day so the difference is small, but over the whole house and the whole winter it can bring significant differences.

The goal of this comparison is to see how PCMs can save energy even in winter. This winter day is chosen because the temperature is cold outside, yet the solar radiation brings heat during the afternoon. Because on these graphs the emphasis is on the energy requirements, the "PCM 21-26" given as best trade-off energy versus comfort is not depicted here. It is indeed not the one bringing the more energy savings for a heating set point of $20^{\circ} \mathrm{C}$. The room was chosen due to its orientation (North facing). It receives solar radiation in the afternoon, and the heating set point of

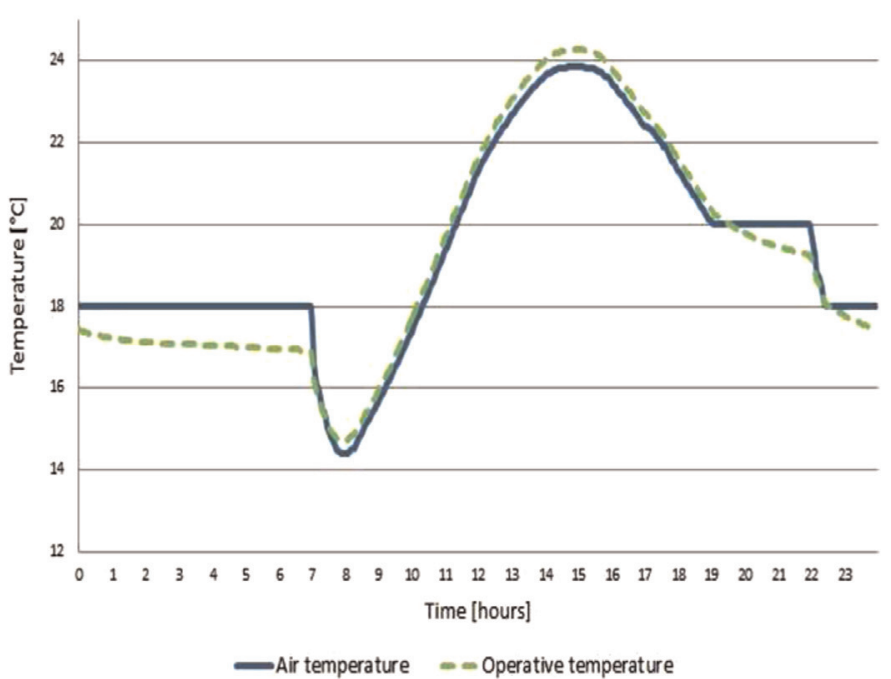

$20{ }^{\circ} \mathrm{C}$ is reached without any heating load at $5 \mathrm{p} . \mathrm{m}$. when people come home. The heat is then released at a different pace in the evening, and at $10 \mathrm{pm}$ the heating set point is lowered to $18{ }^{\circ} \mathrm{C}$ for the night temperature.

The scenario with "No PCM" shows a temperature rise to $24^{\circ} \mathrm{C}$ and then a quick drop until it reaches $20^{\circ} \mathrm{C}$ where the HVAC system activates. The high heating requirements come from the fact that the heat from solar radiation has not been stored in the building's envelope and therefore it needs large loads in the evening and at night.

The design "PCM 20-25" is considered optimum and shows the lowest heating requirements for this heating set point. It is due to the fact that the room can easily reach $20^{\circ} \mathrm{C}$. From there, any solar gain is stored through the melting process and slows down the temperature rise which keeps a relatively constant temperature. The stored heat is then slowly released in the evening and at night, which lowers the heating requirements.

The scenario "PCM 22-27 $20^{\circ} \mathrm{C}$ " is an example of a non-optimum design for a set point of $20^{\circ} \mathrm{C}$. It shows that the temperature rises easily to $22^{\circ} \mathrm{C}$ and then the melting process barely starts. This is due to the fact that in winter the temperature does not go high enough to melt as much PCM as in the previous scenario. Therefore, the temperature drop is slightly slowed down but less energy is stored. The consequence is that the heating requirements are higher than for the other PCM design but lower than the design without PCM.

These graphs show that designs with PCMs bring lower air temperature variations. However what is more interesting is what happens to the operative temperature. It clearly shows that the thermal inertia is significantly increased when a PCM with a melting temperature of $20-25^{\circ} \mathrm{C}$ or $22-27{ }^{\circ} \mathrm{C}$ is selected. Therefore the temperatures take longer time to rise, but also to drop and hence it gives more constant temperature levels. Outside of the phase change temperature range, the designs show relatively similar temperature variations.

The summer day is a typical weekday and it is chosen to show the scenario "No PCM $21^{\circ} \mathrm{C}$ " compared to the scenario "PCM 21$2621^{\circ} \mathrm{C}$ " with a constant cooling set point of $25^{\circ} \mathrm{C}$. The design with PCM, according to Table 3, gives lower energy requirements and also improves comfort. The results for this summer day are given in Fig. 10 and Fig. 11 for the same bedroom as for the winter study. This time, the effect of the PCM is very clear and shows much more constant temperatures over the day. It can be explained by the fact that the temperatures vary across the phase

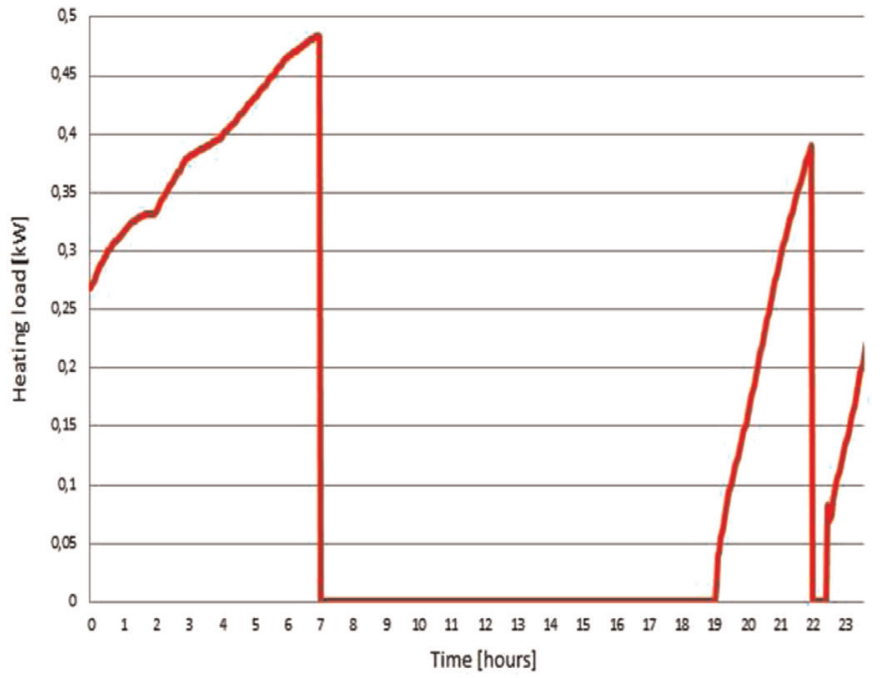

Fig. 7. Analysis over a winter day in a bedroom for the scenario "No PCM $20^{\circ} \mathrm{C}$ ". 

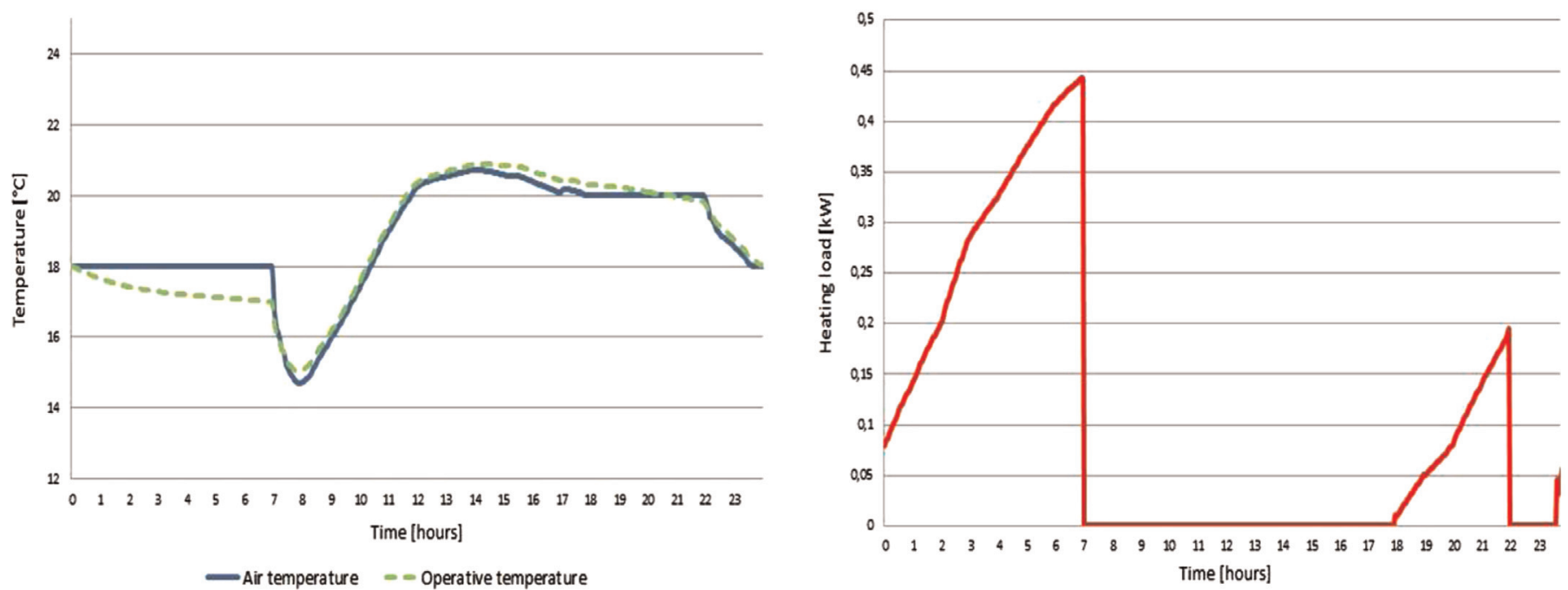

Fig. 8. Analysis over a winter day in a bedroom for the scenario "PCM $20-2520^{\circ} \mathrm{C}$ ".

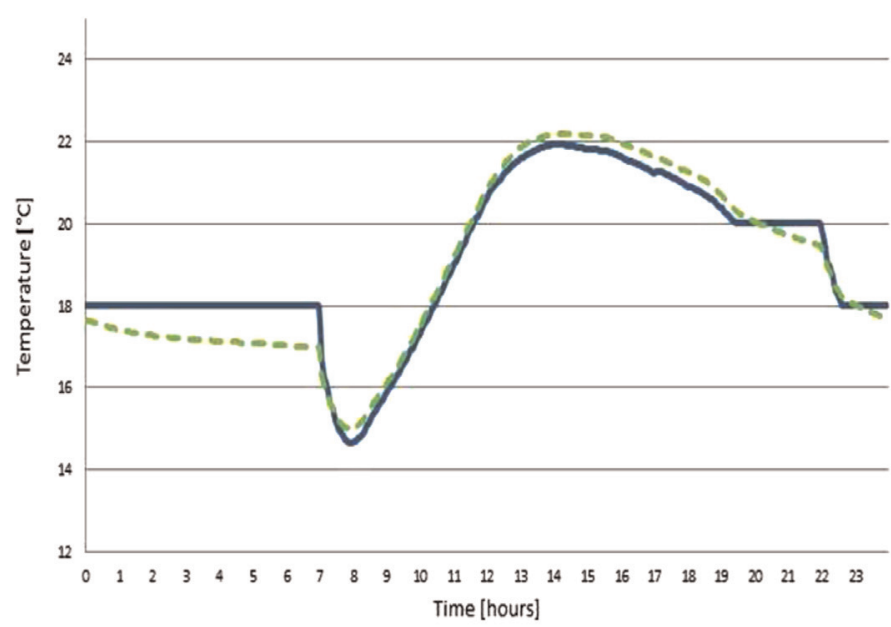

Air temperature $\quad--$ Operative temperature

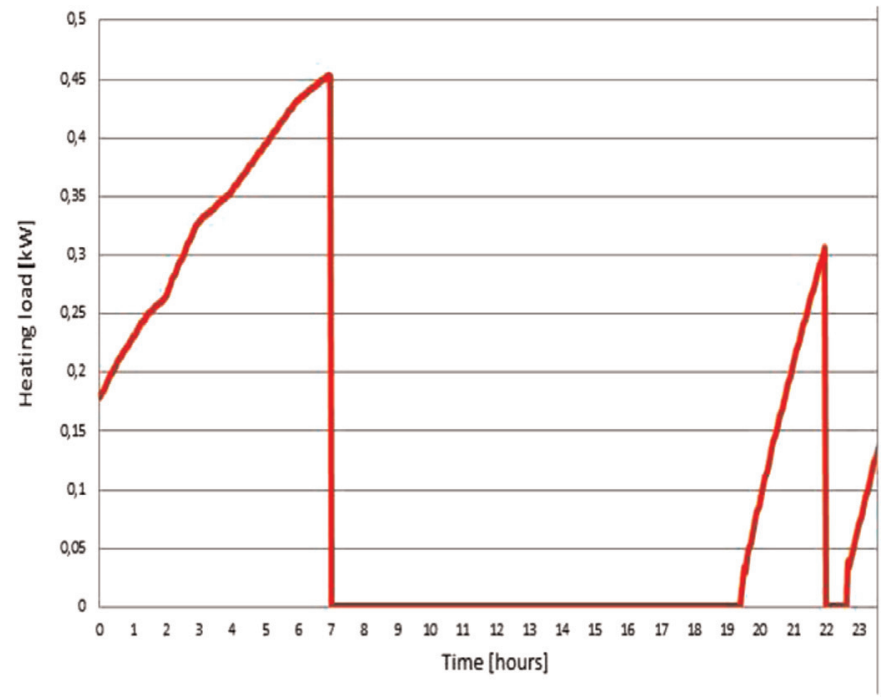

Fig. 9. Analysis over a winter day in a bedroom for the scenario "PCM 22-27 $20^{\circ} \mathrm{C}$ ".

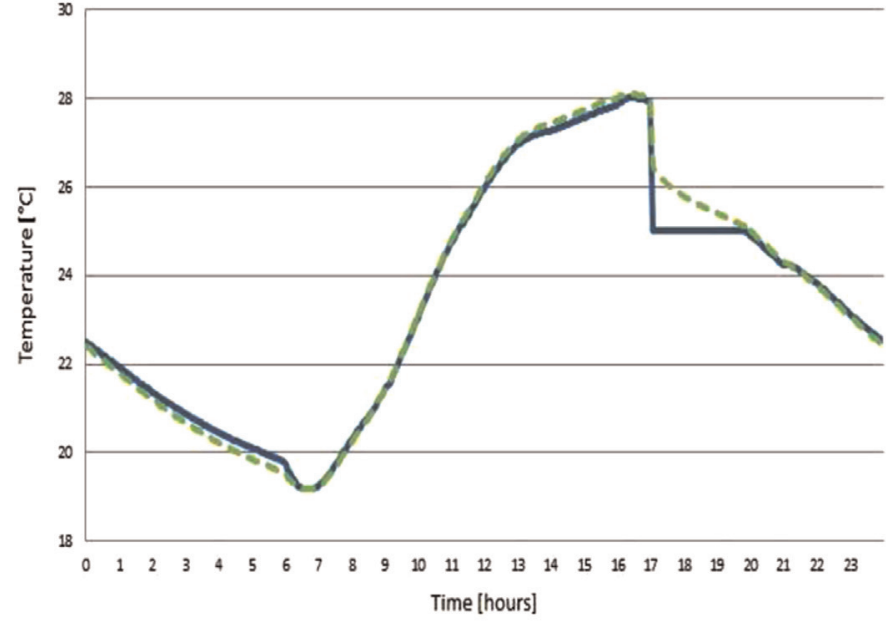

-Air temperature - Operative temperature

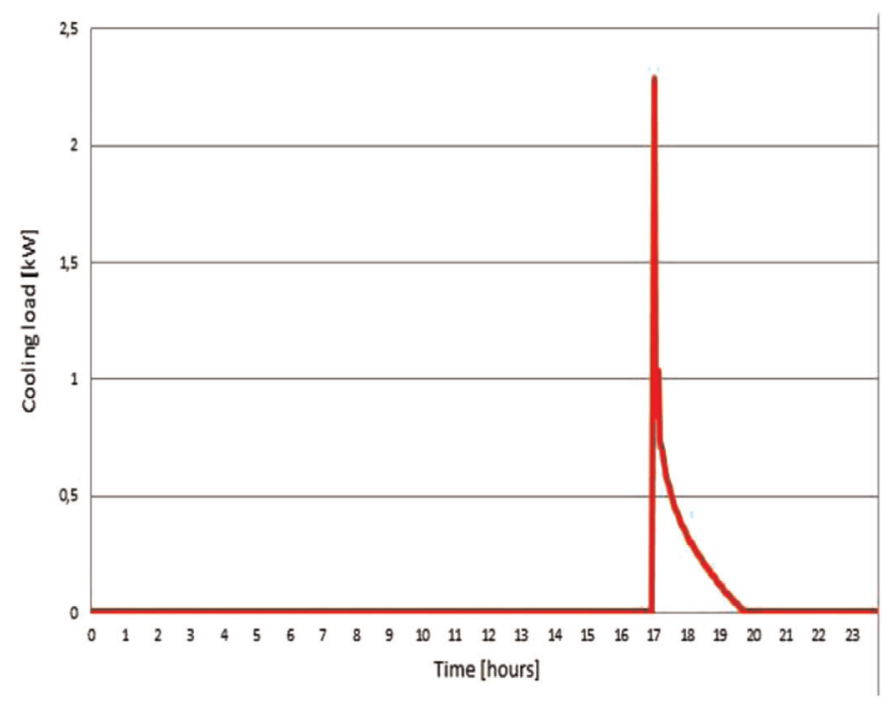

Fig. 10. Analysis over a summer day in a bedroom for the scenario "No PCM $21^{\circ} \mathrm{C}$ ". 

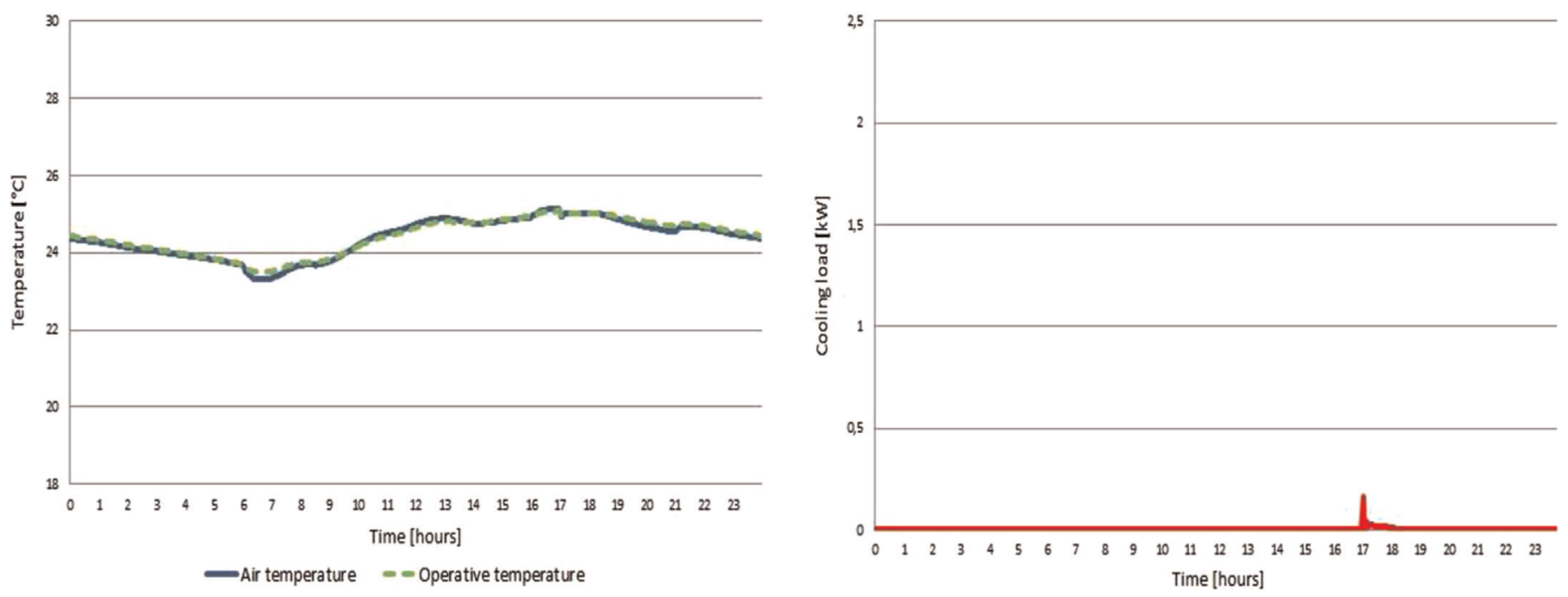

Fig. 11. Analysis over a summer day in a bedroom for the scenario "PCM 21-26 $21^{\circ} \mathrm{C}$ ".

change temperature range. The chosen design has the advantage that the PCM melts and freezes while being in the comfort zone. There are two benefits: first it almost eliminates the need for cooling ( $0.03 \mathrm{kWh}$ versus $0.93 \mathrm{kWh})$, and second it significantly reduces the temperature swing which brings better comfort. The operative temperature varies only within a range of about $1.5^{\circ} \mathrm{C}$ over the whole day versus about $9{ }^{\circ} \mathrm{C}$ for the design without PCM.

This shows that the integration of PCMs can be effective when done properly. Not only does it lowers the cooling needs, but it also brings much more stable temperature and therefore enhances comfort.

\section{Conclusion}

An approach targeting both comfort levels and energy requirements when integrating PCMs into a building was presented in this paper. It was shown how the performance depends on design and operation parameters. Simulation software was used to perform year-round simulations for 30 scenarios and calculate the performance of the building. Depending on the scenario, the results showed significant variations. It is demonstrated that the definition of the comfort (set point temperature) is strongly related to the PCM material used. This indicates that the choice of the right PCM has to be done for a given comfort temperature range.

Regarding the comfort levels, the two types of PCMs which bring the more improvement for any heating set point are the PCMs with a phase change temperature range of $20-25^{\circ} \mathrm{C}$ and $21-$ $26^{\circ} \mathrm{C}$. For energy savings, the results vary strongly depending on the heating set point. A general observation is that most of the savings occur from cooling and only little saving comes from heating. Combining efficiency and comfort indicators, it turns out to be that the PCM with a phase change temperature range of 21$26{ }^{\circ} \mathrm{C}$ is the best regardless of the heating set point.

This highlights the fact that integration of PCM brings significant benefits when the temperatures vary across the phase change temperature range. For better results, this phase change temperature range has to be in the comfort zone.

The integration of PCM into buildings is a complex non-linear problem which shows significant benefits only if well designed. Being weather dependant, the specific designs chosen as optimum for New Zealand might not be the same in other countries. Especially when PCMs are used, a fine tuning of the HVAC set points has to be performed in order to avoid energy losses related to inconsistent design.

\section{Acknowledgments}

The authors thank the University of Auckland for funding the research and providing invaluable support and insights all along the study. The authors would like also to acknowledge the support of the Ministry of Business and Innovation of New Zealand for their support to the PCM activities in the University of Auckland.

\section{References}

[1] J.J. Soares, A.R. Costa, Gaspar, P. Santos, Review of passive pcm latent heat thermal energy storage systems towards buildings energy efficiency, Energy Build. 103 (2013) 59-82.

[2] M.M. Farid, A.M. Khudhair, S.A.K. Razack, S. Al-Hallaj, A review on phase change energy storage: materials and applications, Energy Convers. Manag. 45 (9) (2004) 1597-1615.

[3] L.F. Cabeza, A. Castell, C. Barreneche, A. De Gracia, A.I. Fernández, Materials used as PCM in thermal energy storage in buildings: a review, Renew. Sustain. Energy Rev. 15 (3) (2011) 1675-1695.

[4] X. Jin, M.A. Medina, X. Zhang, On the importance of the location of PCMs in building walls for enhanced thermal performance, Appl. Energy 106 (2013) $72-78$.

[5] L. Shilei, Z. Neng, F. Guohui, Impact of phase change wall room on indoor thermal environment in winter, Energy Build. 38 (1) (2006) 18-24.

[6] Asif Rahman, Michelle E. Dickinson, Mohammed M. Farid, Microencapsulation of a pcm through membrane emulsification and nanocompression-based determination of microcapsule strength, Mater. Renew. Sustain. Energy 1 (1) (2012) 1-10.

[7] (a) A. Castell, M.M. Farid, Experimental validation of a methodology to assess PCM effectiveness in cooling building envelopes passively, Energy Build. 81 (2014) 59-71 2014;

(b) Energy Plus. Documentation [cited 201317 July ]; Available from〈http:// apps1.eere.energy.gov/buildings/energyplus/energyplus_documentation. $\mathrm{cfm}\rangle$.

[8] A. Tardieu. et al. Computer Simulation and Experimental Measurements for an Experimental PCM-Impregnated Office Building, in: Proceedings of the 12th Conference of International Building Performance Simulation Association, 2011, Sydney.

[9] C.L. Zhuang, A.Z. Deng, Y. Chen, S.B. Li, H.Y. Zhang, G.Z. Fan, Validation of veracity on simulating the indoor temperature in PCM light weight building by EnergyPlus. In Life System Modeling and Intelligent Computing, Springer, Berlin Heidelberg (2010) 486-496.

[10] P.C. Tabares-Velasco, C. Christensen, M. Bianchi, Verification and validation of Energy Plus phase change material model for opaque wall assemblies, Build. Environ. 54 (2012) 186-196.

[11] M.M. Behzadi, M.M. Farid, Experimental and numerical investigation on the effect of using phase change materials for energy conservation in residential buildings, HVAC Research 17 (3) (2011) 366-376. 
[12] N. Zhu, S. Wang, Z. Ma, Y. Sun, Energy performance and optimal control of airconditioned buildings with envelopes enhanced by phase change materials, Energy Conver. Manag. 52 (10) (2011) 3197-3205.

[13] The Woolmark Company. The sleeping comfort study 2005 [cited 2013 25th Avril]; Available from 〈http://www.thewoolcompany.co.uk/Sleep\%20Better\% 20with\%20Wool\%20Brochure-emailable.pdf $\rangle$.
[14] Farid, M.M., Private correspondence with PCM manufacturer, 2013: University of Auckland.

[15] Design Builder. Comfort analysis [cited 201317 May ]; Available from:〈http:// www.designbuilder.co.uk/programhelp/comfort_analysis.htm>. 